\title{
The Effect of Positive Horticultural Therapy on the Self-respect, Personality and Talent of Elderly Women
}

\author{
Sung Ju Han* \\ Department of Public Health, Graduate School, Dankook University, Cheonan 31116, South Korea
}

\begin{abstract}
The purpose of the study was to investigate the effect of positive horticultural therapy (PHT) on the self-respect and the personality and talent in elderly women. Elderly women were divided into 2 groups as the control and the experimental group, which performed a positive horticultural therapy program for eight weeks. The results were summarized as follows: self-respect was recognized in all factors of 'Self-confidence, cooperative mind, optimistic mind, satisfaction, self-respect, presence, positive outlook, accomplishment, and sense of excellence' Positive horticultural therapy programs were positively related to improving self-respect and quality of life of the elderly women $(p<.01)$. The personality and talent score of the experimental group was higher than that of the control group in all factors: ' $[\mathrm{t}] \mathrm{he}$ pursuit of meaning, personal relationships, reliability, sincerity/acceptance, compassion, sympathy, being earnest, responsibility, self-awareness, altruism, respect and praise for others, and grace' $(p<.01)$. Also it can be confirmed that it has a positive effect on the mental, physical, and social lives of the elderly women. Therefore, positive horticultural therapy with horticultural therapy and positive psychology, be confirms that the above results are very useful for improving the self-respect and quality of life in elderly women; also, it can be suggested that the above results are very useful for improving self-respect or quality of life of various objects.
\end{abstract}

Key words: positive psychology, personality strength, self-esteem, therapeutic horticulture

\section{I . Introduction}

As elderly people experience various physical, psychological, and social changes, they feel a great sense of isolation and anxiety, and become more isolated in social relationships. In particular, elderly women face various psychological problems caused by financial instability after retirement and by changes in their roles in society and family, and such accumulated problems result in many physical, financial, and psychological issues including feelings of loneliness and alienation, and a fear of death (Go et al., 2001; Gwon, 2016; Han, 1998; Kim, 1981; Seong, 1997).

Rapid social changes such as urbanization undermine people's self-esteem, and the development of urban civilization starts to be recognized just as a means to maintain the social system, making people feel isolated and emotionally weak (Heo, 2003; Relf, 1981). Such phenomena happen to general people, and especially to the elderly population.

Received on February 16, 2017. Revised on February 22, 2017.

Accepted on April 11, 2017.

*Comesponding author: send2esther.h@gmail.com
Kim (1999) pointed out that a wide range of programs were provided to improve the quality of life of the elderly, but that such welfare programs for the elderly mostly focused on either educational programs such as computer and English or recreational programs such as body exercise, yoga, and singing.

Recently, various horticultural therapy programs have been developed and provided to increase the psychological stability of the elderly and their desire to live through eco-friendly horticultural activities such as planting. Hwang (2002) and Jung et al. (2001) found that horticultural therapy programs improved the psychological, emotional, social, and cognitive abilities of the elderly. In another study, it was found that positive horticultural therapy programs stimulated and developed the positive aspects of humans through various gardening activities and that creative horticultural activities combined with positive psychology, effectively improved people's quality of life and particularly promoted their creative sense of accomplishment, positive emotions and interpersonal relationships (Lee, 2008).

Joo (2010) reported that positive horticultural therapy was effective to enhance people's sense of responsibility by achieving 
personal goals or shared goals of groups, to create positive relationships by building sympathy and supportive relationships with others through various approaches, and thus to improve their interpersonal relationships, sociality and personality. However, there have been few studies on specialized therapy programs combined with positive psychology to restore the psychological, emotional and social relationships between humans and plants, and between humans and other humans.

In this study, the "6 virtues and 24 character strengths" suggested by Seligman (2011) were divided into internal and external elements, and internal character strengths including love, mercy, compassion, grace, altruism, etc. were defined as "personality," and external character strengths including teaching, healing, aiding, nurturing, etc. as "talent" expressed as external behaviors.

Thus, this study aimed to examine the effect of integrated positive horticultural therapy, provided to build relationships between humans and plants, on the self-respect, personality, and talent of elderly women.

\section{Methods}

\section{Subjects and methods}

In this study, a horticultural program was provided after acquiring written consent from individual participants and permission from the Institutional Review Board (IRB) of Dankook University (IRB No. DKU 2016-07-006). The program was provided for elderly women who were aged over 65 and members of I Church located in Goyang-si, Gyeonggi-do, Korea. The status of the self-respect, personality, and talent of participants was surveyed by a professional horticultural therapist (2nd grade certification issued by the Korean Horticultural Therapy Association) through one-to-one interviews before and after conducting the program. In this study, a total of 40 participants were divided into two groups as shown in Table 1: 20 people as the control group (intact group) and 20 people as the experimental group (treatment group).

Those in the experimental group participated in 8 sessions of the positive horticultural therapy (PHT) program: once a week, 90 120 minutes per session. The PHT program was supported and intervened with the positive emotion, engagement, relation- ships, meaning, and achievement categories of Seligman (2011), and the program was led by one $1^{\text {st }}$-grade horticultural therapist, and one $2^{\text {nd }}$-grade horticultural therapist (Joo, 2010).

\section{Plans and contents of PHT}

The PHT used in this study was conducted to stimulate and develop the positive aspects of humans and to improve their quality of life by restoring their self-respect, personality, and talent. To do so, participants were supported to build positive emotions, and positive interpersonal relationship skills between groups, to feel a sense of accomplishment through engagement, and to have a positive view toward life by inspiring them. In detail, first, participants repeatedly experienced positive emotions through horticultural activities. Second, they were had higher interest in and felt the pleasure of engaging in horticultural activities with various species of plants. Third, plants and horticultural activities were used as a medium to build their interpersonal relationship skills for better communication within family and other groups. Fourth, they were encouraged to have a higher hope for life and higher self-esteem through the meaning of the cycle of plants. Last, they felt a sense of accomplishment and had higher confidence through the results and outcomes of horticultural activities and plants. The program used in this study was designed with the therapeutic and educational concept model to enable participants to be in the happiest and healthiest state by inducing them to engage voluntarily in various new horticultural activities (Joo, 2010; Seligman, 2011; Woo, 2014) (Figure 1). In particular, this PHT program (Table 1) was composed and executed by comprehensively integrating the results of the preliminary interview survey on their psychological and physical characteristics.

\section{Assessment tools}

In this study, the following assessment tools were used to measure changes in the self-respect, personality and talent of elderly women. "Self-respect"was composed of 9 sub-factors including a sense of excellence, self-respect, accomplishment, satisfaction, presence, cooperative mind, optimistic mind, positive outlook, and self-confidence. "Personality and talent" were composed of 12 sub-factors including being earnest, grace, sympathy, compassion, responsibility, reliability, self-awareness, 
Table 1. Positive horticultural therapy (PHT) combined with the positive psychology.

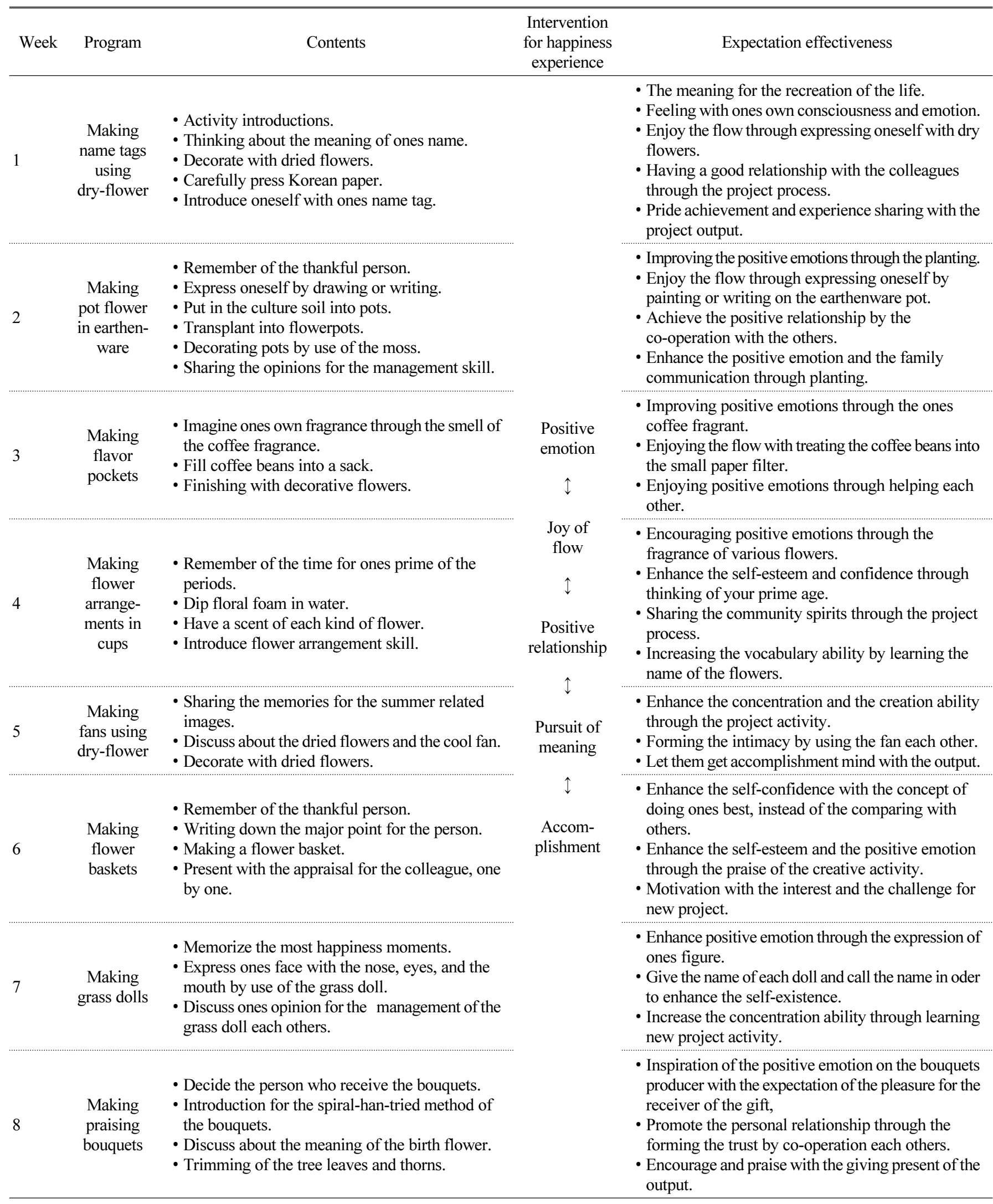


altruism, respect and praise for others, sincerity and acceptance, pursuit of meaning, and personal relationships.

To measure the level of self-respect, the positive self-respect scale developed by Rosenberg (1965) was used. The scale was composed of 9 questions, and each question was evaluated with a 5-point Likert scale as follows: 1=strongly disagree, $2=$ disagree, $3=$ not sure, $4=$ agree, and $5=$ strongly agree. The reliability of the scale was Cronbach's alpha $=.89$, indicating the scale was a suitable tool for social science research. It was known that the higher the score of the self-respect assessment, the higher self-respect the person has (Kim, 2003; Kim, 2004; Son, 2015).

To measure the level of personality and talent, the 12-question simplified version of the 240-question assessment questionnaire developed by Seligman (2014) was used. The reliability of the questionnaire was Cronbach's alpha $=.93$, indicating that it was a suitable tool for social science research. The questionnaire was also evaluated with the same Likert scale used to measure self-respect. The higher the score, the stronger personality and talent the person has (Seligman, 2011; Woo, 2014).

The homogeneity of the self-respect, personality, and talent of the control and experimental groups, and the levels before and after participating in the PHT program were statistically analyzed using an independent samples t-test. The data of the two groups before and after the program were compared using SSPS (Statistical Package for Social Science) ver. 21.0, and a paired t-test was used to statistically compare the data.

\section{Results and Discussion}

\section{Homogeneity test of PHT program participants}

The average age of participants in the control and experimental groups before participating in the PHT program was 72 73 years. The results of the homogeneity test on the selfrespect, personality, and talent of the two groups did not show any statistically significant difference, and thus it was possible to assume that the two groups were identical (Table 2).

2. The effect of the PHT program on self-respect

The results of the independent samples t-test on all the variables in the control and experimental groups before the PHT program showed no statistically significant difference $(p>.05)$. However, the results of the t-test on all the sub-

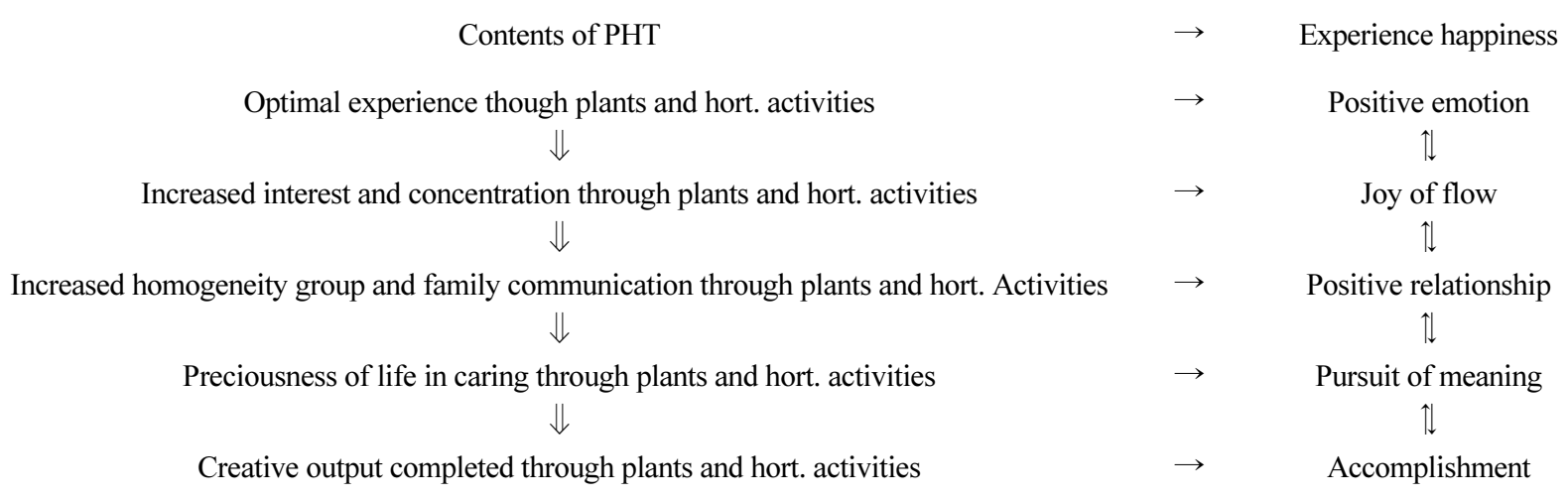

Fig. 1. Concept of applying positive horticultural therapy (PHT).

Table 2. Homogeneity test in the score of self-respect and personality and talent between the control and the experiment groups.

\begin{tabular}{lcccc}
\hline \multicolumn{1}{c}{ Factor } & Control group & Experiment group & T & $p$-value \\
\hline Age & $71.85 \pm 7.46^{\mathrm{z}}$ & $72.60 \pm 5.29$ & & .754 \\
Self-respect & $22.65 \pm 2.78$ & $20.60 \pm 4.47$ & $1.759^{\mathrm{NS}}$ & $.095^{\mathrm{NS}}$ \\
Personality and talent & $27.40 \pm 3.74$ & $29.55 \pm 4.17$ & 1.720 & \\
\hline
\end{tabular}

${ }^{\mathrm{z}}$ Mean \pm Standard deviation.

${ }^{\mathrm{NS}}$ Non significant at $p<.05$ by independent t-test. 
factors of self-respect in the two groups after the PHT program showed highly statistically significant differences $(p<.01)$. The results of the paired samples t-test on all the sub-factors in the experimental group after the PHT program were higher than those before the PHT program, and there were statistically significant differences before and after the program $(p<.01)$.

The results of all the sub-factors in the experimental group were significantly higher than those in the control group, in the order of sense of excellence, self-respect, accomplishment, satisfaction, presence, cooperative mind, optimistic mind, positive outlook, and self-confidence, as shown in Table 3. In total, the result of the self-respect of the experimental group greatly increased from $20.60 \pm 4.47$ before the PHT program to $38.45 \pm 2.76$ after the PHT program compared to that of the control group.
In particular, the result of "sense of excellence" of the experimental group showed the highest increase from $1.65 \pm$ 0.59 before the PHT program to $4.45 \pm 0.51$ after the PHT program, followed by "accomplishment" from $1.55 \pm 0.60$ to $4.20 \pm 0.60$, and self-respect from $1.65 \pm 0.75$ to $4.25 \pm 0.64$. These results confirmed that the PHT program was highly effective to improve the self-respect of elderly women, and that all the sub-factors had a positive impact on it. According to Joo (2010), when providing PHT programs for those who were diagnosed with diseases, or those who went through medical incidents, their interest in and hope for life, and their sense of confidence and accomplishment can be improved by their positive emotions, pleasure from engaging in activities, smooth interpersonal relationships, and creativity. In this study, it was also found that the PHT program had a highly positive impact

Table 3. Effect of positive horticultural therapy (PHT) on self-respect in elderly women.

\begin{tabular}{|c|c|c|c|c|c|c|c|}
\hline Item & Group & $\mathrm{N}$ & Before & $\begin{array}{c}\text { Independent } \mathrm{t} \text {-test } \mathrm{t}^{\mathrm{z}} \\
(p \text {-value })\end{array}$ & After & $\begin{array}{c}\text { Independent } \mathrm{t} \text {-test }^{\mathrm{y}} \\
(p \text {-value })\end{array}$ & $\begin{array}{c}\text { Paired t-test }^{\mathrm{x}} \\
(p \text {-value })\end{array}$ \\
\hline \multirow{2}{*}{ Sense of excellence } & Control & 20 & $1.85 \pm 0.67$ & \multirow{2}{*}{$.322^{\mathrm{NS}}$} & & \multirow{2}{*}{$.001^{* *}$} & $.090^{\mathrm{NS}}$ \\
\hline & Experimental & 20 & $1.65 \pm 0.59$ & & $4.45 \pm 0.51$ & & $.001^{* *}$ \\
\hline \multirow{2}{*}{ Self-respect } & Control & 20 & $2.00 \pm 0.65$ & \multirow{2}{*}{$.080^{\mathrm{NS}}$} & $2.20 \pm 0.83$ & \multirow{2}{*}{$.001^{* *}$} & $.330^{\mathrm{NS}}$ \\
\hline & Experimental & 20 & $1.60 \pm 0.75$ & & $4.25 \pm 0.64$ & & $.001^{* *}$ \\
\hline \multirow{2}{*}{ Accomplishment } & Control & 20 & $1.90 \pm 0.79$ & \multirow{2}{*}{$.123^{\mathrm{NS}}$} & $2.30 \pm 0.57$ & \multirow{2}{*}{$.001^{* *}$} & $.008^{*}$ \\
\hline & Experimental & 20 & $1.55 \pm 0.60$ & & $4.20 \pm 0.60$ & & $.001^{* *}$ \\
\hline \multirow{2}{*}{ Satisfaction } & Control & 20 & $2.30 \pm 0.73$ & \multirow{2}{*}{$.451^{\mathrm{NS}}$} & $2.55 \pm 1.10$ & \multirow{2}{*}{$.001^{* *}$} & $.330^{\mathrm{NS}}$ \\
\hline & Experimental & 20 & $2.15 \pm 0.49$ & & $4.15 \pm 0.37$ & & $.001^{* *}$ \\
\hline \multirow{2}{*}{ Presence } & Control & 20 & $1.85 \pm 0.88$ & \multirow{2}{*}{$1.000^{\mathrm{NS}}$} & $1.95 \pm 0.69$ & \multirow{2}{*}{$.001^{* *}$} & $.694^{\mathrm{NS}}$ \\
\hline & Experimental & 20 & $1.85 \pm 0.81$ & & $3.45 \pm 0.60$ & & $.001^{* *}$ \\
\hline \multirow{2}{*}{ Cooperative mind } & Control & 20 & $2.70 \pm 0.57$ & \multirow{2}{*}{$.105^{\mathrm{NS}}$} & $2.55 \pm 0.83$ & \multirow{2}{*}{$.001^{* *}$} & $.481^{\mathrm{NS}}$ \\
\hline & Experimental & 20 & $2.25 \pm 1.07$ & & $3.65 \pm 0.49$ & & $.001^{* *}$ \\
\hline \multirow{2}{*}{ Optimistic mind } & Control & 20 & $2.70 \pm 0.57$ & \multirow{2}{*}{$.402^{\mathrm{NS}}$} & $2.90 \pm 0.91$ & \multirow{2}{*}{$.001^{* *}$} & $.297^{\mathrm{NS}}$ \\
\hline & Experimental & 20 & $2.50 \pm 0.89$ & & $3.75 \pm 0.44$ & & $.001^{* *}$ \\
\hline \multirow{2}{*}{ Positive outlook } & Control & 20 & $2.60 \pm 0.68$ & \multirow{2}{*}{$.582^{\mathrm{NS}}$} & $2.65 \pm 0.75$ & \multirow{2}{*}{$.001^{* *}$} & $.748^{\mathrm{NS}}$ \\
\hline & Experimental & 20 & $2.45 \pm 1.00$ & & $3.70 \pm 0.47$ & & $.001^{* *}$ \\
\hline \multirow{2}{*}{ Self-confidence } & Control & 20 & $2.65 \pm 0.59$ & \multirow{2}{*}{$.221^{\mathrm{NS}}$} & $2.65 \pm 0.81$ & \multirow{2}{*}{$.001^{* *}$} & $1.000^{\mathrm{NS}}$ \\
\hline & Experimental & 20 & $2.40 \pm 0.68$ & & $3.60 \pm 0.50$ & & $.001^{* *}$ \\
\hline \multirow{2}{*}{ Total } & Control & 20 & $22.65 \pm 2.78$ & \multirow{2}{*}{$.089^{\mathrm{NS}}$} & $24.90 \pm 6.16$ & \multirow{2}{*}{$.001^{* *}$} & $.059^{\mathrm{NS}}$ \\
\hline & Experimental & 20 & $20.60 \pm 4.47$ & & $38.45 \pm 2.76$ & & $.001^{* *}$ \\
\hline
\end{tabular}

\footnotetext{
${ }^{z} p$-value between the control group and the experimental group, before treatment by use of the independent $\mathrm{t}$-test.

${ }^{\mathrm{y}} p$-value between the control and the experimental, after treatment by use of the independent t-test.

${ }^{x} p$-value on the difference before and after the treatment within group by the paired t-test.

${ }^{\mathrm{NS}}$ Non significant; ${ }^{*} p<.05 ; * * p<.01$.
} 
on the self-respect of elderly women, and, in particular, that the program improved their quality of life significantly. The results coincided with other earlier studies. For instance, Lee (2012) reported that elderly women compared their life with the cycle of plants, and became more confident in their existence and life while growing plants and seeing the life cycle of plants (Lee, 2012). The results were also similar to those of other earlier studies that both healthy and unhealthy elderly people became more emotionally stable and had a higher sense of accomplishment through activities of touching and arranging flowers and plants (Han et al., 2009; Kim and Yoo, 2010; Yoon and Kim, 2009).

The experimental group showed the smallest increase in the sub-factor of "presence" from $1.85 \pm 0.81$ before the PHT program to $3.45 \pm 0.60$ after the PHT program. The results indicated that experiences of participating in the PHT program in person and sharing their skills with others gave an opportunity to feel their presence to elderly people who had experiences of farming and eco-friendly life in their younger days (Yoon et al., 2009).

\section{The effect of the PHT program on personality and} talent

The results of the independent samples t-test on all the variables in the control and experimental groups after participating in the PHT program showed no statistically significant difference $(p>.05)$. However, the results of the t-test on most of the variables in the experimental group after participating in the PHT program were higher than those in the control group, showing statistically significant differences $(p<.01)$, except the sub-factor of "personal relationships" which had no statistically significant difference between the control and experimental groups $(p>.05)$. The results of the paired samples t-test on all the factors in the experimental group showed a statistically significant difference $(p<.01)$. However, the results of the sub-factors of "pursuit of meaning" and "reliability" in the control group were slightly higher after the PHT program than before the PHT program $(p<.05)$, but the results of the subfactors of "responsibility" and "altruism" were lower after the PHT program than before the PHT program $(p<.05)$.

The results of all the sub-factors of personality and talent in the experimental group were higher than those in the control group, in the order of being earnest, grace, sympathy, compassion, responsibility, reliability, self-awareness, altruism, respect and praise for others, sincerity and acceptance, pursuit of meaning, and personal relationships as shown in Table 4. In total, the score of the personality and talent of the experimental group greatly increased from $29.55 \pm 4.17$ before the PHT program to $44.60 \pm 3.1$ after the PHT program.

In particular, the sub-factors of "being earnest" and "responsibility" are associated with teamwork, civic awareness and a sense of justice, and in particular the result of "being earnest" showed the highest increase from $2.65 \pm 0.93$ before the PHT program to $4.75 \pm 0.44$ after the PHT program. These results were similar to those of earlier studies that mentally and physically weakened elderly people who no longer played social roles could strengthen their roles within plant-human, or human-human groups, become more open to interactions with members and more eager to perform their duties, improve their sociality, and have a higher sense of reward and self-respect (Cho, 2006; Lee and Sim, 2004; Lim, 2010; Yoon, 2001; Zajicek, 1997).

The result of the sub-factor of "grace" in the experimental group increased from $2.75 \pm 1.16$ before the PHT program to $4.75 \pm 0.44$ after the PHT program, the second highest following "being earnest." The sub-factor of "sympathy," meaning kindness, love and affection to humanity, showed a significantly high increase both in the control and experimental groups from $2.20 \pm 0.83$ before the PHT program to $3.85 \pm 0.49$ after the PHT program. These results were similar to those of the study of Park and Yoo (2007) that horticultural activities enabled people to recognize the value of life, to be more considerate to living things, and to put themselves in others' position with positive thinking. These results showed that the PHT program had positive effects on elderly women through activities of caring for plants.

The sub-factors of "pursuit of meaning" meaning sociality and "reliability" meaning honesty also showed a significant increase after the PHT program, which indicated that such PHT programs were effective to encourage people to form positive emotions through creative activities using various plants, to improve their sociality and positive interpersonal relationships with others through positive horticultural therapy, and to feel grateful to others and have a higher hope for their 
life through vital and recreative horticultural activities. In particular, these results were similar to those of a study on positive psychology that found that horticultural activities stimulating five senses allowed people to discover their present ego and enjoy a meaningful and happier life with positive attitudes (Woo, 2014).

In this study, it was found that the PHT program had a positive impact on the personality and talent of elderly women, positively healing their sense of physical and mental isolation through eco-friendly horticultural activities.
Meanwhile, close and positive interpersonal relationships with family members and other groups play an important role in improving elderly women's satisfaction with their life, and these close relationships not only enhance their ability to understand themselves, but also build confidence to overcome negative situations such as stress and a sense of isolation. Activities used in this program such as making flower pots using earthenware, making flower arrangement in cups, making grass dolls, and making name tags and fans with pressed flowers strengthened a sense of closeness with others (Table

Table 4. Effect of positive horticultural therapy (PHT) on personality and talent in elderly women.

\begin{tabular}{|c|c|c|c|c|c|c|c|}
\hline Item & Group & $\mathrm{N}$ & Before & $\begin{array}{c}\text { Independent } \mathrm{t} \text {-test } \mathrm{t}^{\mathrm{z}} \\
(p \text {-value })\end{array}$ & After & $\begin{array}{c}\text { Independent } \mathrm{t} \text {-test } \mathrm{t}^{\mathrm{y}} \\
(p \text {-value })\end{array}$ & $\begin{array}{c}\text { Paired t-test } \\
(p \text {-value })\end{array}$ \\
\hline \multirow{2}{*}{ Being earnest } & Control & 20 & $2.40 \pm 0.94$ & \multirow{2}{*}{$.404^{\mathrm{NS}}$} & $2.40 \pm 0.68$ & \multirow{2}{*}{$.001^{* *}$} & $1.000^{\mathrm{NS}}$ \\
\hline & Experimental & 20 & $2.65 \pm 0.93$ & & $4.75 \pm 0.44$ & & $.001^{* *}$ \\
\hline \multirow{2}{*}{ Grace } & Control & 20 & $2.20 \pm 1.01$ & \multirow{2}{*}{$.118^{\mathrm{NS}}$} & $2.20 \pm 0.77$ & \multirow{2}{*}{$.001^{* *}$} & $1.000^{\mathrm{NS}}$ \\
\hline & Experimental & 20 & $2.75 \pm 1.16$ & & $4.75 \pm 0.44$ & & $.001^{* *}$ \\
\hline \multirow{2}{*}{ Sympathy } & Control & 20 & $1.85 \pm 0.88$ & \multirow{2}{*}{$.203^{\mathrm{NS}}$} & $1.90 \pm 0.64$ & \multirow{2}{*}{$.001^{* *}$} & .748 \\
\hline & Experimental & 20 & $2.20 \pm 0.83$ & & $3.85 \pm 0.49$ & & $.001^{* *}$ \\
\hline \multirow{2}{*}{ Compassion } & Control & 20 & $2.00 \pm 0.73$ & \multirow{2}{*}{$.833^{\mathrm{NS}}$} & $1.70 \pm 0.57$ & \multirow{2}{*}{$.001^{* *}$} & .055 \\
\hline & Experimental & 20 & $2.05 \pm 0.76$ & & $3.55 \pm 0.51$ & & $.001^{* *}$ \\
\hline \multirow{2}{*}{ Responsibility } & Control & 20 & $2.25 \pm 0.72$ & \multirow{2}{*}{$.668^{\mathrm{NS}}$} & $1.60 \pm 0.75$ & \multirow{2}{*}{$.001^{* *}$} & $.002^{* *}$ \\
\hline & Experimental & 20 & $2.15 \pm 0.75$ & & $3.65 \pm 0.59$ & & $.001^{* *}$ \\
\hline \multirow{2}{*}{ Reliability } & Control & 20 & $2.70 \pm 0.92$ & \multirow{2}{*}{$.080^{\mathrm{NS}}$} & $3.05 \pm 0.94$ & \multirow{2}{*}{$.001^{* *}$} & $.005^{*}$ \\
\hline & Experimental & 20 & $3.20 \pm 0.83$ & & $4.60 \pm 0.68$ & & $.001^{* *}$ \\
\hline \multirow{2}{*}{ Self-awareness } & Control & 20 & $2.20 \pm 1.06$ & \multirow{2}{*}{$1.000^{\mathrm{NS}}$} & $2.40 \pm 0.94$ & \multirow{2}{*}{$.002^{* *}$} & $.104^{\mathrm{NS}}$ \\
\hline & Experimental & 20 & $2.20 \pm 0.70$ & & $3.15 \pm 0.37$ & & $.001^{* *}$ \\
\hline \multirow{2}{*}{ Altruism } & Control & 20 & $2.10 \pm 0.72$ & \multirow{2}{*}{$.832^{\mathrm{NS}}$} & $1.60 \pm 0.60$ & \multirow{2}{*}{$.001^{* *}$} & $.014^{*}$ \\
\hline & Experimental & 20 & $2.05 \pm 0.76$ & & $3.00 \pm 0.00$ & & $.001^{* *}$ \\
\hline \multirow{2}{*}{ Respect / praise for others } & Control & 20 & $2.80 \pm 0.77$ & \multirow{2}{*}{$.070^{\mathrm{NS}}$} & $2.70 \pm 1.08$ & \multirow{2}{*}{$.001^{* *}$} & $.606^{\mathrm{NS}}$ \\
\hline & Experimental & 20 & $3.30 \pm 0.92$ & & $4.25 \pm 0.55$ & & $.001^{* *}$ \\
\hline \multirow{2}{*}{ Sincerity / acceptance } & Control & 20 & $2.35 \pm 0.99$ & \multirow{2}{*}{$.595^{\mathrm{NS}}$} & $2.20 \pm 0.70$ & \multirow{2}{*}{$.001^{* *}$} & .379 \\
\hline & Experimental & 20 & $2.20 \pm 0.77$ & & $3.05 \pm 0.39$ & & $.001^{* *}$ \\
\hline \multirow{2}{*}{ Pursuit of meaning } & Control & 20 & $2.15 \pm 0.81$ & \multirow{2}{*}{$.125^{\mathrm{NS}}$} & $2.55 \pm 1.00$ & $007^{* *}$ & $.002^{* * *}$ \\
\hline & Experimental & 20 & $2.60 \pm 0.99$ & & $3.35 \pm 0.75$ & .001 & $.001^{* *}$ \\
\hline Personal relationshins & Control & 20 & $2.40 \pm 0.99$ & $508^{\mathrm{NS}}$ & $2.10 \pm 0.79$ & $050^{\mathrm{NS}}$ & $.055^{\mathrm{NS}}$ \\
\hline Personal relationships & Experimental & 20 & $2.20 \pm 0.89$ & .508 & $2.65 \pm 0.99$ & .059 & $.009^{* *}$ \\
\hline & Control & 20 & $27.40 \pm 3.74$ & $005^{\mathrm{NS}}$ & $26.40 \pm 4.48$ & $001^{* *}$ & $.192^{\mathrm{NS}}$ \\
\hline Total & Experimental & 20 & $29.55 \pm 4.17$ & .09 & $44.60 \pm 3.1$ & .001 & $.001^{* *}$ \\
\hline
\end{tabular}

${ }^{z} p$-value between the control group and the experimental group, before treatment by use of the independent t-test.

${ }^{y} p$-value between the control and the experimental, after treatment by use of the independent $t$-test.

${ }^{\mathrm{x}} p$-value on the difference before and after the treatment within group by the paired t-test.

${ }^{\mathrm{NS}}$ Non significant; $* p<.05 ; * * p<.01$. 
4). Such activities were found to contribute to providing an opportunity to witness changes in plants and create the cycle of plants from birth to death to re-birth (Lewis, 1996), and to improve people's sociality to respect the value of life and others such as sub-factors like pursuit of meaning, personal relationships, sympathy, acceptance, altruism, respect for others, and grace (Cho, 2006; Davis, 1994; Lee et al., 2000; Lee and Sim, 2004).

The result of the sub-factor of "personal relationships" increased from $2.20 \pm 0.89$ before the PHT program to $2.65 \pm 2.65$ after the PHT program, indicating the smallest statistically significant difference among other sub-factors. These results were similar to those of Son et al. (2006) that found that rediscovering people's own role in a group increased their sociality, and in particular had a positive impact on the sociality of elderly women.

The effects of the PHT program used in this study were comprehensively analyzed, and it was found that all the subfactors of the personality and talent of elderly women including "being earnest, grace, sympathy, compassion, responsibility, reliability, self-awareness, altruism, respect and praise for others, sincerity and acceptance, pursuit of meaning, and personal relationships" showed very positive results in the experimental group after the PHT program. Thus, it is believed that such PHT programs will be very effective to improve the self-respect and the quality of life of various groups of people as well as elderly women.

\section{Conclusions}

The PHT program was provided for elderly women, and the effects of the PHT program on the self-respect, personality, and talent of participants were as follows.

All the sub-factors of self-respect including "sense of excellence, self-respect, accomplishment, satisfaction, presence, cooperative mind, optimistic mind, positive outlook, and selfconfidence" showed statistically positive differences $(p<.01)$, indicating that the PHT program had a positive impact on the self-respect and the quality of life of elderly women.

All the sub-factors of personality and talent including "being earnest, grace, sympathy, compassion, responsibility, reliability, self-awareness, altruism, respect and praise for others, sincerity and acceptance, pursuit of meaning, and personal relationships" in the experimental group after the PHT program showed much higher results than in the control group $(p<.01)$, indicating that the PHT program also had a positive impact on the mental, physical and social abilities of elderly women.

As shown above, this study found that the PHT program combining horticultural therapy and positive psychology was very effective to strengthen the self-respect and personality of elderly women, and that it could be very useful to improve the self-respect and the quality of life of various groups of people.

\section{References}

Cho, N.H. 2006. Effect of horticultural therapy on the improvement of self-esteem and sociality of the low-income group children. MS thesis, Konkuk Univ., Seoul, Korea.

Davis, S. 1994. Ninth annual congressional initiatives award ceremonies. Senate Russell Office Building, Washington, DC, USA.

Go, S.D., M.R. Son, and Y.S. Choi. 2001. A study on the relationship of the geriatric depression to the elderlys general characteristics. Korean J. Fam. Welf. 6(1):3-10.

Gwon, J.D. 2016. Welfare for the aged. Hakjisa, Seoul, Korea.

Han, M.J. 1998. A study on the relationship between the self-esteem and the attitude toward death of the aged. Seoul Women Univ., Student Life Study 10:137-159.

Han, K.H., S.M. Lee, and J.G. Suh. 2009. Effect of group horticultural therapy on the change of depression and self-esteem in older adult. J. Korean Soc. People Plants Environ. 12(4):1-12.

Heo, E.J. 2003. The effects of intergenerational activities in the day care center. Ph.D Diss., Wonkwang Univ., Jeonbuk, Korea.

Hwang, I.O. 2002. A study on a strategy for strengthening the social adaptation of the dementia aged through horticultural therapy. Ph.D Diss., Busan Natl. Univ., Busan, Korea.

Joo, E.Y. 2010. Positive horticultural therapy. Edambooks, Gyeonggido, Korea.

Jung, J.E., K.W. Lee, and W.K. Sim. 2001. Relation between leisure and life satisfaction of the older adults with the participation in horticultural activities. J. Korean Soc. People Plants Environ. 4(1):17-25.

Kim, G.J. 2003. Effect of horticultural therapy on the changes of depression and self-esteem of demented old adults. MS thesis, Honam Univ., Gwangju, Korea.

Kim, K.H. 2004. The relationship among leisure participation style, family strength, powerlessness, self-esteem and happiness of elderly. Ph.D Diss., Kookmin Univ., Seoul, Korea.

Kim, S.Y., 1999. The effect of group reminiscence therapy on pain, depression and self-esteem of the elderly - Focused on institutional elderly with chronic pain. J. Korean Acad. Adult Nurs. 11(1): 50-62.

Kim, T.H. 1981. A study on the elderly support in Korea. Ph.D Diss., 
Korea Univ., Seoul, Korea.

Kim, Y.S. and Y.K. Yoo. 2010. Effects of horticultural therapy on the self-esteem and emotion in older adult with brain lesion. J. Korean Soc. People Plants Environ. 13(2):1-6.

Lee, M.H., S.H. Park, S.Y. Lim, E.K. Jeong, and J.K. Suh. 2000. A study for preference of older adult about horticultural therapy program. J. Korean Soc. People Plants Environ. 3(4):31-37.

Lee, E.S. and W.K. Sim. 2004. Effects of group horticultural activities as a leisure on the isolation and life satisfaction of the solitude elderly female. J. Korean Soc. People Plants Environ. 7(3):31-37.

Lee, H.S. 2008. Positive psychology, Sigmapress. Co., Ltd., Seoul, Korea.

Lee, H.J. 2012. Effects of horticultural therapy program using reminiscence stimulation materias on cognition and depression of the eldery with dementia. Dankook Univ., Cheonan, Korea.

Lewis, C.L. 1996. Green nature / Human nature: The meaning of plants in our lives. Univ. of Illinois Press, Chicago, USA.

Lim, E.A. 2010. Development of evaluation indices of horticultural therapy and examination of its efficacy. Ph.D Diss., Konkuk Univ., Seoul, Korea.

Rosenberg, M. 1965. Society and adolescent self-image (Vol. 11, p. 326). Priceton, NJ: Princeton Univ., Press, Princeton, USA.

Park, E.J. and Y.K. Yoo. 2007. Effects of horticultural activities on the social, psychological, and emotional behaviors in kindergarten pupil. J. Korean Soc. People Plants Environ. 10(4):124-130.

Relf, P.D. 1981. Dynamics of horticultural therapy. Rehabil. Lit. 42(5-6):147-150.
Seligman, M.E.P. 2011. Flourish : A visionary new understanding of happiness and well-being. Free Press, New York, USA.

Seligman, M.E.P. 2014. Authentic happiness : Using the new positive psychology to realize your potential for lasting fulfillment. Mulpure publishing, Inc., Gyeonggido, Korea.

Seong, G.W. 1997. Degree of cognitive function, self- esteem and depression of the elderly by aging. J. Acad. Nurs. 27(1):36-48.

Son, K.C., M.K. Cho, J.E. Song, S.Y. Kim, and S.S. Lee. 2006. Practice of professional horticultural therapy. Kubook, Seoul, Korea.

Son, M.R. 2015. Effect of horticultural therapy on school life adaptation and stress of juvenile. Ph.D Diss., Wonkwang Univ., Jeonbuk, Korea.

Woo, M.S. 2014. Happiniess 4.0. Mulpure publishing, Inc., Gyeonggido, Korea.

Yun, S.Y. and H.Y. Kim. 2009. Effect of horticultural therapy program linked to children on life satisfaction of elders in facilities. J. Korean Soc. People Plants Environ. 12(2):9-14.

Yoon, S.K. 2001. The effect on the plant culture working on changes in children's personality. MS thesis. Seoul Natl. Univ., of Education, Seoul, Korea.

Yun, S.Y., B.J. Choi, and H.Y. Kim. 2009. The Effects of Flower Arrangement on the Balance of Feelings and Depression of Hospitalized Elders. J. Korean Soc. People Plants Environ. 12(6): $1-5$.

Zajicek, J.M. 1997. Introduction and overview of opportunities in interdisciplinary research in children's gardening. HortScience 32(3):556 (Abst. \# 739). 
